\title{
Does the Department of Basic Education Take the International Call to Provide Quality Education for all Seriously?
}

\author{
E. C. du Plessis and M. M. Mbunyuza* \\ Department of Curriculum and Instructional Studies, University of South Africa, \\ P. O. Box 392, UNISA, 0003, South Africa \\ "Telephone: (012) $4294441,{ }^{*} E$-mail: mbunynmm@unisa.ac.za
}

KEYWORDS Critical Theory. Curriculum and Assessment Policy Statement. National Curriculum Statement. Qualitative Research. Socio-constructivism. Training of Teachers

\begin{abstract}
Governments, across the globe are accountable for training teachers to provide learners with quality education to face the challenges of globalisation and curriculum change. Arising from this challenge, the Department of Basic Education (DBE) in South Africa introduced, over the last decade, several curriculum changes, which had an influence on the delivery of quality education for all. The present research focuses on the question of whether the DBE can train in-service teachers and provide quality learning and teaching support materials (LTSM) to comply with the challenges of the implementation of a new national curriculum, the Curriculum and Assessment Policy Statement (CAPS). The theoretical frameworks for this study are based on social constructivist and critical theory constructs. A qualitative research approach has been employed in this study. Data collection consisted of a literature review, document analysis and collection of empirical evidence. The findings revealed that CAPS is being implemented impulsively, without proper in-service training or the provision of quality LTSM to schools. This paper concludes with recommendations concerning the DBE's role in assistance of in-service training.
\end{abstract}

\section{INTRODUCTION}

The concept of the research seeded during a news broadcast on a news channel in South Africa (eNews 2012) on 15 June 2012 at 08: 00, "5 000 schools in Limpopo province (one of nine provinces in South Africa) don't have textbooks ....” This was despite the provincial Department of Basic Education (DBE) having been placed under administration in December 2011 and having received a deadline to deliver textbooks to more than 5000 Limpopo schools. According to Beeld of 3 October 2012, 37 248, books had still not been delivered to schools in Polokwane (Limpopo province) (Fourie 2012). A recent report published by the World Economic Forum (WEF) has ranked the quality of South Africa's mathematics and science education last out of 148 countries (Wilkenson 2014). Poor results was also highlighted by Lekota (2014) when he described the quality of South African school education as mediocre following the announcement

Address for correspondance:

Dr. E. C. du Plessis

Professor

P. O. Box 392

UNISA, 0003, South Africa

Telephone: (012) 4294033

Fax: +27866343996

E-mail: dplesec@unisa.ac.za of the 2013 matric pass rate by Basic Education Minister Angie Motshekga. Taken together, these circumstances, point to an urgent need for proper support to be provided to individual schools and to the whole education system so as to make it possible for curriculum modifications to have a positive impact on education. According to the Constitution of the Republic of South Africa 1996, all learners have a right to education (Government of South Africa 1996). This was confirmed by the president of South Africa, president Zuma when he mentioned that South Africa is confronted by "the triple challenges of poverty, inequality and unemployment". Education is the key to creating transformation in these areas. Our Bill of Rights stipulates that every citizen has the right to basic education, including adult basic education and further education (Ngubane 2014).

The research undertaken for this paper focused on the challenges faced by the DBE to provide quality education for all. In addition, curriculum change is discussed against the background of critical theory. The research paradigm adopts both a constructivist (socio-constructivism) as well as a critical theory viewpoint and includes a qualitative research approach. This exploratory research type uses literature review, document analysis and empirical evidence (in- 
terviews) as research methods. The research closes with a critical discussion of the findings.

\section{Objectives of the Study}

The objective of the study is to determine if the DBE in South Africa provide quality education by investigating if teachers were coping or not coping with the new curriculum and to determine what type of in-service training they receive, if at all.

\section{Theoretical Framework}

Education is part of the social context for cognitive development. Social constructivism is a sociological theory of knowledge that applies general philosophical constructivism to social settings wherein groups construct knowledge for one another, thus collaboratively creating a small culture of shared artefacts with shared meanings. When one is immersed within a culture of this sort, one is learning all the time about how to be a part of that culture on many levels. The origins of social constructivism are largely attributed to Lev Vygotsky (Vygotsky 1978).

The authors refer to Vygotsky's characteristic of constructivism social constructivism because he emphasised the critical importance of culture and the importance of the social context for cognitive development. Social constructivism is essentially a theory about how people socially construct knowledge (Vygotsky 1978).

A constructivist teacher creates a context for learning in which students can become engaged in interesting activities that both encourage and facilitate learning. The teacher does not simply stand by and watch learners explore and discover. Instead, he or she may often guide learners as they approach problems, may encourage them to work in groups to think about issues and questions, and may support them with encouragement and advice as they tackle problems, adventures, and challenges rooted in real life situations that are both interesting and satisfying to learners in terms of the results of their work. Teachers thus facilitate cognitive growth and learning, as do peers and other members of the child's community (Vygotsky 1962; Kalpana 2014).

All classrooms, in which instructional strategies compatible with Vygotsky's social constructivist approach are used, do not necessar- ily look alike. The classroom activities undertaken and the format thereof can vary considerably. A central notion in socio-constructivism is assisted learning and its concept of proximal learning (when a child is helped in learning a concept in the classroom with the assistance of more able peers) (Kalpana 2014).

Critical theory, as the second theoretical framework, is particularly suitable within the area of education and power (Cho 2006). Within much of critical theory, power is often considered as structural processes that produce false consciousness. Power in this case is referring to government and the DBE.Proponents of critical theory are to seek to reveal society for what it is, to unmask its essence and mode of operation, and to lay the foundations for human emancipation through deep-seated social change (Gibson and Gareth 1979). The educational task, therefore, is to analyse and understand these processes so that consciousness can become fully itself. Such a view of the relationship between power and emancipation is found in the work of Wolfgang Klafki:

Education in the sense of critical theory must therefore necessarily become a permanent critique of society, and the aim of such effort is to help the individual to self-determination and emancipation ... (Klafki 1983: 105).

At its core, critical pedagogy has the following two major agendas: Transformation of knowledge (for example, curriculum) and pedagogy (in a narrow sense that is, teaching). The most significant focus of critical pedagogy is the relationship between knowledge and power. By asserting that knowledge is intrinsically interwoven with power, critical pedagogy adamantly and steadfastly dismisses the mainstream assumption of knowledge as objective and neutral (Cho 2006).

Based on this premise that knowledge is power, ideology critique and discourse analysis are employed as powerful conceptual tools in elucidating the interconnectedness between knowledge and power (Cho 2006). Are governments using power to change curriculum rather than asking how to organise and deliver school knowledge most efficiently to learners (like training teachers when a new curriculum is implemented)? Apple (1979) captured and summarised the questions of a new curriculum in the following three truncated questions: 1) Whose knowledge?; 2) For whose benefit?; and 3) At whose 
expense? This form of critical theory is a way of thinking about curriculum change in relation with policymakers (DBE), classroom teaching, the production of knowledge, school structures and available resources.

Some critical theorists, however, do tackle aspects such as No Child Left Behind (NCLB), and the neo-liberal view on globalisation (Apple 2001; Apple and Buras 2006; Giroux 2004). This aspect is underlined to determine if the new curriculum in South Africa makes provision for all learners. In addition, certain critical pedagogists have consistently emphasised the importance of the relations between macro-power dynamics (such as the DBE) in larger society and micro-power relations within educational institutions (such as schools) (Giroux and McLaren 1994). As critical pedagogy relies on experiences (everyday politics), it also tends to be geared towards an anti-structure, anti-system approach for inventing democratic classroom and school cultures.

Another political project is to reform, fundamentally, educational and other social institutions to make them more inclusive, based on desirable principles - whatever the underlying principles for the reform of the system are, be they equality, equal rights, anti-discrimination, democracy, emancipation, common goods, individual liberty, recognition, peace, or social justice. The guarantee of equal opportunity and equal power for the underprivileged, oppressed, marginalised, or subjugated is a major concern. The project of inclusion could be understood as having similar veins of reason as "rights-based" liberalism and multiculturalism (Giroux 1992; Giroux and McLaren 1994; Darder et al. 2003, 2004). These new terminologies seem to be an attempt to differentiate and distance critical pedagogy from mainstream "inclusive" multiculturalism, which would explain the calls, among critical pedagogues, to go beyond the mainstream approaches of inclusion to more critical multiculturalists approaches: "insurgent multiculturalism” (Giroux 1995), "revolutionary multiculturalism” (McLaren and Farahmandpur 2001), and “subaltern cosmopolitan multiculturalism” (Buras and Motter 2006). With critical pedagogy now having been inserted into the backdrop of the larger historical developments in the politics of social movements, the following literature review links with these ideas.

\section{Literature Review}

\section{Social Science}

Social science is the field of study concerned with society and human behaviours. It is commonly used as an umbrella term to refer to a plurality of fields outside of the natural sciences. These include: Anthropology, archaeology, criminology, economics, history, linguistics, political science and international relations, sociology, geography, education, law, and psychology (Verheggen and Baerveldt 1999; Garai and Kocski 1995). Social sciences emanated from the moral philosophy and were influenced by the Age of Revolutions (which encompassed the Industrial Revolution and the French Revolution) (Renato 1993). This emphasises the moral responsibility of the DBE to provide education for all.

Education encompasses teaching and learning specific skills, and also something less tangible but more profound: The imparting of knowledge, positive judgement and well-developed wisdom. Education has as one of its fundamental aspects the imparting of culture from generation to generation (socialisation). To educate means "to draw out" from the Latin educare or to facilitate the realisation of pedagogy, a body of theoretical and applied research relating to teaching and learning and draws on many disciplines such as psychology, philosophy, computer science, linguistics, neurosciences, sociology and anthropology (Wikipedia 2012). The sociology of education is the study of how education institutions determine social structures, experiences, and other outcomes. It is particularly concerned with the schooling systems of modern industrial societies (Wikipedia 2012).Both curriculum and teaching form essential parts of education as a whole.

\section{Curriculum Change in South Africa}

Since 1994, South Africa has experienced a great deal of educational transformation. This has been necessary because of the situation inherited by the first democratic government. The previous government was a minority White, apartheid government. Following the 1994 elections, one of the first tasks of the National Education and Training Forum was to begin a process to revise national syllabi and to have cer- 
tain subjects rationalised. The purpose of this was to lay the foundation for a single national core syllabus and the creation of a single national Department of Education (DoE) from the 19 racially, ethnically, and regionally divided "departments of education" (Jansen and Taylor 2003).

One of the most challenging aspects of this transformation was the adoption of an Outcomes-based Education (OBE) approach that underpinned the introduction of the new curriculum, Curriculum 2005 (C2005). OBE is widely considered to have its roots in two educational approaches: The competency-based education movement and mastery of learning. Competency-based learning aims to prepare learners for success in fulfilling various life roles. William Spady, who first presented his OBE framework in 1988, led the development of an OBE model derived from competency-based learning (Kramer 1999).

In March 1997, the then Minister of Education, Sibusiso Bengu, launched C2005 and announced a process through which the new curriculum would be phased in from 1998 to 2005. This is how the adoption of OBE and the development of C2005 took place (Kramer 1999). In 2000, the Minister of Education set up a Curriculum Review Committee. This led to a modification of the curriculum, the National Curriculum Statement (NCS), with a more "streamlined" approach (Department of Education 2000). In 2002 the curriculum was reconstructed once again into a Revised National Curriculum Statement or 'RNCS' that was implemented in 2004 (Department of Basic Education 2010). In 2006, the DoE issued The National Policy Framework for Teacher Education and Development in South Africa, a policy which, it stated, "has been a long time in preparation, and is certainly overdue given the state of our education system" (Department of Education 2008).

In 2010, the curriculum was reconstructed once again, because of complaints by various stakeholders. According to the Minister of Basic Education Angie Motshekga, the following steps were taken (Department of Basic Education 2010):

- a reduction in the number of projects for learners

- a discontinuation of the need for portfolio files of learner assessment
- a reduction in the number of teachers' files to a single one

- the discontinuation of Common Tasks for Assessment (CTAs) for Grade 9 learners from January 2010

- tests for Grades 3 and 6 to be set nationally

- the establishment of three committees to implement the new curriculum, namely:

- the Curriculum and Assessment Policy Statements Ministerial Project Committee (the Subject Learning Area by Grade guidelines were known as the Curriculum and Assessment Policy Statements (CAPS), to be implemented over two years)

- the Committee for the Reduction of Learning Areas in the Intermediate Phase in the General Education and Training (GET) band (the NCS with its eight learning areas for the Intermediate Phase would be repackaged into six learning programmes, known as subjects)

- the Learning and Teaching Support Materials Committee (this includes the distribution of learning and teaching support packs for Grade R teachers, as well as lesson plans in literacy and numeracy for Grades 1-6)

During 2011 the NCS was replaced by the Curriculum and Assessment Policy Statement (CAPS) after the Minister of Basic Education appointed a panel of experts to investigate the nature of the challenges and problems experienced in the implementation of the NCS (Department of Basic Education 2009, 2011; Pinnock 2011).The CAPS is an adjustment to what we teach (curriculum) and not how we teach (teaching methods) (Pinnock 2011).

\section{What is CAPS?}

The Curriculum and Assessment Policy Statement (CAPS) is not a new curriculum, but an amendment to the National Curriculum Statement (NCS) Grades R-12. It therefore still follows the requirements of the same process and procedure as the National Curriculum Statement Grades R-12 (2002) (Pinnock 2011).

There is much debate and discussion about OBE being removed - however, OBE is a method of teaching, not a curriculum. It is the curriculum that has changed (been repackaged) and not the teaching method. The curriculum is now written in content format rather than in outcomes format. This means that traditional teacher meth- 
ods are more likely to be used, rather than $\mathrm{OBE}$ methods, because OBE failed in many ways in South Africa. There is one single comprehensive National Curriculum and Assessment Policy for each subject. The CAPS document is very much subject specific and fixed (Du Plessis 2013).

The NCS and CAPS documents have a similar rationale in terms of situating the curriculum within the aims of the South African Constitution. In addition, the NCS includes a rationale and description of OBE and a large amount of information on the background and history of the NCS. In both NCS and CAPS mention is made of the curriculum conveying the knowledge, skills and values that should be communicated in a post-apartheid South Africa. Both contain a similar list of values, which includes social justice, human rights, environmental awareness and respect for people from diverse cultural, religious and ethnic backgrounds. The similarities and differences between the documents are summarised in Table 1.

\section{Responsibility of the Department of Basic Education - Training of Teachers}

Constant professional in-service training and development of teachers are necessary for the security of any education system. However, the curriculum changes have been so far-reaching that it has been impossible to train all teachers even for the NCS adequately through the regular support services available to the DBE (Lessing and De Witt 2007). Consequently, the DBE has decided to contract teacher training institutions to assist with continuous professional development. Teachers were not trained in the previous curriculum (NCS) and, in September 2010, yet another policy (CAPS) was introduced (Department of Basic Education 2010). According to Coetzee (2012), Grade 3 teachers missed out on CAPS training during 2011 even though CAPS was supposed to have been implemented in the foundation phase (Grades R-3) in 2012. Implementation of CAPS took place before training of teachers.

Coetzee (2012) agrees that one of the areas in which teachers experience the most problems is assessment. Conflicting information regarding the assessment policy does the education system no favours. For example, in 2008, the Director-General of Education sent a circular to all schools in order to introduce revised progres- sion and promotion requirements, which were to be implemented in 2010(Department of Basic Education 2010). However, the Report of the Ministerial Task Team on the Review of the Implementation of the NCS advised that there should be further changes to the progression requirements in order to strengthen assessment. In the light of this, the Director-General's Circular of 2008 to schools was withdrawn; instead all schools had to note the following: The changes that were introduced to schools in the Circular of 2008 would not be implemented.

Until further notice, all schools will use the existing assessment policy in GET and the provisions for assessment in the National Policy on the Protocol for Assessment: Reporting and Recording. This arrangement will continue until the CAPS have been developed and implemented in schools (Department of Basic Education 2010). Since the distribution of Curriculum News 2010 in December 2009/January 2010, officials in the DBE have received many questions and comments regarding the changes introduced from the beginning of 2010 . Two of these questions asked by teachers and answered by the $\mathrm{DBE}$ are highlighted for the purpose of this paper (Department of Basic Education 2010):

Question: "My school has not received a copy of the Foundations for Learning and Teaching Pack that includes lesson plans for literacy, numeracy and life skills, learners' workbooks and resource books, as well as posters and story books for the Foundation Phase. How does my school get copies?"

Answer: "The Learning and Teaching Pack was for Grade R in the Foundation Phase. At the moment we do not have any additional packs ...”

Question: “Are there any clear guidelines for teachers on how to plan and manage school projects?"

Answer: "The requirements for school projects will vary from subject to subject and teacher to teacher. It is best for teachers to learn from and share information with one another in a school or cluster and teacher unions and/or associations on projects.”

It may be concluded from the above that conflicting information as well as inadequate material and guidelines provided by the DBE are an indication that not all structures are in place, including provision for continuous professional development. It is widely accepted that the 
Table 1: Summary of core changes from NCS to CAPS

\begin{tabular}{lll}
\hline Concept / feature / dimension & NCS & CAPS \\
\hline Structure of Qualification & $\begin{array}{l}\text { Gr R to 9 (as outlined in } \\
\text { RNCS 2002)GETC mentioned in } \\
\text { overview document, with exit } \\
\text { level at Gr 9GETC never }\end{array}$ & $\begin{array}{l}\text { CAPS = Gr R to 12GETC is not mentioned in } \\
\text { CAPSOnly exit level is at Gr 12 (NSC) } \\
\text { Conceptual shift to 13 years of schooling as } \\
\text { the new norm }\end{array}$
\end{tabular}

Critical Outcomes

Development Outcomes

Purpose(S)

Principles

Inclusivity

Outcomes / Objectives

Assessment Link

Planning

Integration

Role of Teacher and Learner
Reflect on and explore a variety

Also incorporated in aims and curriculum Explicitly practice

content and skillsCAPS phrases Critical Outcome 2 as "work effectively as individuals and with others as members of a team" (specific reference to individuals)

of strategies to learn more effectively.Participate as responsible citizens in the life of local, national and global communities.Be culturally and aesthetically sensitive across a range of social contexts.Explore education and career opportunities. Develop entrepreneurial opportunities.

Outlined as: Equipping learners, No explicit list of purposes given (but a similar irrespective of their socioeconomic background, race, gender, physical ability or intellectual ability, with the knowledge, skills and values necessary for self-fulfilment and meaningful participation in society as citizens of a free country; providing access to higher education; facilitating the transition of learners from education institutions to the workplace; and providing employers with a sufficient profile of a learner's competences

NCS = OBE, described as "participatory, learner-centred and activity-based education" Mentioned in passing

Learning outcomes

Assessment Standards

Phase plan

Work schedules

Learning programme

development

Lesson plans

Principle of coherence between

the learning areas made explicit

Teacher role described as: "key

contributor to transformation

of education in South Africa";

"qualified, competent, dedicated

and caring"; "able to fulfil the

various roles outlined in the

Norms and Standards for

Educators: these include
CAPS = "encouraging an active and critical approach to learning, rather than rote and uncritical learning of given truths"

Foregrounded and described in detail as one of the general aims

Concepts, content and skills

Content / Assessment

Overview across grades

Overview of year plan

Subject interpretation of curriculum content for instructional designs

Lesson plans

Not mentioned

No mention of the envisaged teacherLittle room for interpretation of what and how to teach 
Table 1: Contd...

\begin{tabular}{lll}
\hline Concept / feature / dimension & NCS & CAPS \\
\hline & $\begin{array}{l}\text { being mediators of learning, } \\
\text { interpreters and designers of } \\
\text { Learning Programmes and } \\
\text { materials, ..." etc.; "considerable } \\
\text { room for creativity and } \\
\text { innovation on the part of } \\
\text { teachers in interpreting what } \\
\text { and how to teach" } \\
\text { Learner to participate as group } \\
\text { member (focus on group work) } \\
\text { Discovery-based learning }\end{array}$ & $\begin{array}{l}\text { Focus on learner taking individual } \\
\text { responsibility for learning } \\
\text { Content-driven learning; no emphasis on } \\
\text { critical thinking about knowledge validity and } \\
\text { bias }\end{array}$ \\
& &
\end{tabular}

Source: Adapted from Department of Basic Education, 2011(a) and (b).

initial professional education of teachers is only the foundation of their professional education (Teacher Education 2010). Indeed, the development of professional practices is a continuing process that lasts for the duration of the career of a committed teacher. Continuous professional development is the process by which teachers (like other professionals) reflect on their competences, keep themselves up to date and develop themselves further (Teacher Education 2010).

Smith and Gillespie (2007) state that professional development can be effective if it is designed to be of longer duration (longer than a few days) - longer-term professional development permits more time for teachers to learn about their own practice, especially if it includes follow-up training, focuses on subject-matter knowledge and includes a strong emphasis on analysis and reflection, rather than just on demonstrating techniques. It should also include a variety of teaching activities and should encourage teachers from the same workplace to participate together in teaching opportunities. Furthermore, it should focus on quality and features of professional development, rather than on format or type of training.

Continuing professional teacher development is an essential component of a high-quality comprehensive teacher education system, as envisaged in the Minister of Education's $\mathrm{Na}$ tional Policy Framework for Teacher Education and Development (Department of Education 2008). A continuing professional teacher development system has six main purposes:

- to improve schooling and the quality of learner achievements
- to coordinate professional development activities with a view to achieving sharper focus and effectiveness

- to revitalise the teaching profession and foster commitment to the profession's seminal role in the development of the country

- to contribute to the responsible autonomy and confidence of the teaching profession

- to enable the profession to re-establish its professional standing and role in advancing the ideals of social justice

- to acknowledge the effective participation of teachers in professional development this is a priority for the education system and the teaching profession.

This system is managed and administered by the South African Council for Educators (SACE), supported by the DBE. It consists of professional development activities, endorsed by SACE, for which educators earn professional development points. Teachers are expected to earn a target of 150 points in each successive rolling three-year cycle (Department of Education 2008).

The SACE task team has already identified risks and problems regarding the implementation of the new continuing professional teacher development system (Department of Education 2008). A few of these problems are as follows:

- Funding to the system may not be sustained.

- The new professional development policy may not be communicated clearly or effectively to teachers in schools. An aggravating factor is that teachers' morale is low in general (Coetzee 2012). Backlogs in school infrastructure, resources and administrative support, and teachers' workloads, may be 
inhibiting professional teacher development. Providers such as the Department of Basic Education may not have the capacity to support teachers' developmental needs.

- The provincial departments of education may not have the capacity to support the system.

Against the background of the theoretical framework, the literature review and in an effort to establish if the DBE is providing quality education for all, the researchers' questions are: How do teachers cope, or not cope with the new curriculum and the type of in-service training they receive or do not receive? In the following section, we provide answers to these questions with reference to the findings of an empirical research project (Du Plessis 2013).

\section{METHODOLOGY}

The research paradigm for this research is two-fold. It is based on a post-positivist paradigm as well as a constructivist paradigm. The motivation is confirmed by the two theoretical frameworks, namely socio-constructivism and critical theory. The researchers used a qualitative research approach to study the issue of the responsibility of the DBE to train teachers in order for them to provide quality education for all. According to Struwig and Stead (2013) qualitative research extends the understanding of a phenomenon and contributes to educational practice, policymaking and social consciousness. Qualitative designs emphasise understanding of social phenomena through direct observation, communication with participants, or analysis of texts, and may stress contextual and subjective accuracy over generality (Wikipedia 2012). Therefore, the research project involved a qualitative research approach aimed at probing in-depth teachers' views and perspectives on their training and teaching experience regarding CAPS (Du Plessis 2013).

Purposive and convenient samplings were used to select teachers from different schools. In purposive sampling, researchers purposefully seek typical and divergent data within easy reach (convenient sampling) (de Vos et al. 2011). A selection of 15 different schools (11 primary and four secondary schools) from the General Education and Training (GET) and Further Education and Training (FET) bands in schools was used as a sample of a bigger population.
Data were gathered using an interview schedule to interview participants regarding the inservice training they had received to implement a new curriculum. The interview schedule consisted of two sections, the first covering biographical detail and the second seeking information about the type of in-service training teachers had received. Interviews were recorded verbatim and transcribed by the researcher. Data were grounded by hand coding for internal consistency. Comparisons were drawn to point out generalisations and contrasts. The ethical considerations adhered to by the researcher included gaining informed consent from the school principals and participants involved. Further, participation was voluntary and anonymous and confidentiality was assured. Trustworthiness was attended to through verification measures such as comparison of responses, which were acquired to identify and confirm specific trends and patterns in the data. The researchers aimed at reporting the participants' viewpoints, thoughts, intentions and experiences accurately by making use of direct quotations from participants' responses.

\section{RESULTS}

\section{In-service Training of Teachers and the Implementation of the New Curriculum}

The results in the first section on the participants' (teachers') biographical data were as follows: 73 percent of the participants consisted mainly of female teachers, teaching in different schools in the GED (75 percent) and FET (15 percent) bands. Most of the participating teachers had more than 20 years' teaching experience.

In the second section the researchers asked questions about the type and length of in-service training regarding CAPS teachers had attended. Participants were asked to describe the type of in-service training regarding CAPS which they attended, for example, how many hours, by whom? They were asked if their school principals attended any CAPS training or not. According to the participants, training varied from twohour workshops to three-day workshops. Training providers were curriculum advisers from district offices, subject advisers and publishing companies. One female participant, teaching Grade 2 learners, indicated that she had not attended any CAPS workshops and that she had 
received the CAPS documents from the principal. Most of the participants indicated that their school principals had not received any CAPS training and, if they had, it was simply in the form of a meeting for the introduction of CAPS or to receive the CAPS documents on CD.

The next question was intended to identify the main changes from NCS to CAPS. The following were some of the points mentioned: Learning areas had been changed to subjects, time allocated to Home Language and First Additional Language had been changed; there were now specific concepts or topics defined for each grade. The Home Language and Mathematics pass marks had changed from 35 percent to 50 percent and 40 percent, respectively. The following was stated by a male Grade 10 teacher: "We no longer talk in terms of learning outcomes and assessment standards. Teaching is more teacher-centred than it was under NCS (which was learner-centred)".

Participants were asked what they found positive about CAPS. According to them, they found subject content to be clearly stated for each grade. Teachers stated that they now engaged themselves in lesson preparations rather than in lesson plans and that this also benefited learners. They reported that there were fewer tasks to do and that there had been a reduction in teachers' administrative and written work. They were of the opinion that the changes would produce learners able to identify and solve problems and make decisions and that the learners would be able to think critically and creatively.

In response to a question regarding what was negative about CAPS, the following matters were raised: Subject Advisers were not felt to be sufficiently involved during training and not enough intensive CAPS workshops had been presented. No textbooks had been delivered to schools yet. CAPS was not felt to cater for learner diversity or for learners with special educational needs. No in-depth workshops had been conducted. CAPS was felt to have been implemented prematurely as educators were not equipped with relevant knowledge. According to a female Grade 3 teacher, time given to timetables is very limited. She testified that it is “...too much work to fit into one period”. It was felt that, if schools did not receive proper support and training from the DoE that they could not function properly. CAPS was also felt to be very prescriptive and static.
Participants were asked to make recommendations and the following were among those put forward: Workshops must be for a month and subject specific; textbooks must be delivered on time to schools; paperwork must be reduced so that educators may have good contact with learners; and implementation and monitoring workshops must be conducted for school management teams and principals.

\section{DISCUSSION}

Reflecting back on the literature - contradictory information (as stated in the distribution of Curriculum News 2010) (Department of Basic Education 2010) as well as insufficient material and guidelines seem to be among the problems experienced when implementing a new curriculum. This is also alluded to by Ngubane (2014) where he stated that the DBE is tasked with leadership, policymaking and the monitoring responsibility of improving the quality of learning and ensuring quality, sustained education, but fails to do it properly. According to the participants, CAPS is now very structured and fixed and teachers are teaching according to prescribed text. This is not in line with social constructivism where the teacher creates a context for learning and mediates learning. These fixed structures might discourage the creative teacher.

The question of political power to implement another curriculum is the order of the day. Since democracy in South Africa (1994), unemployment has increased from 22.8 percent in 2008 to 24.7 percent in 2013 (Lund 2014). According to statistician-general Pali Lehohla "there was only one reason why unemployment levels were still highest among black Africans 20 years into democracy -poor education" (Lund 2014).

The researchers' considerations about the implementation of CAPS are societal expectations and it is the responsibility of the DBE to provide in-service training for teachers to implement a new curriculum, to be able to provide quality education for all. The question of stakeholders and input from teachers can be questioned. In addition to this is the problem of sufficient in-service training - which in this case seems to be lacking, as pointed out by Coetzee (2012) that teachers missed out on CAPS training in the foundation phase. It is clear from the data that in-service training is a huge problem and that training is done in a general way and is 
not subject specific. Critical theory requires us to be a "critic of society", therefore the competencies of the DBE can be questioned in terms of delivery of quality education (including inservice training of teachers) and the provision of LTSM. Quality of education is also a concern for Lekota (2014) who believes that the quality of South-African education is mediocre as he made the following statement: "South Africa's productivity has steadily declined in the past few years and this is directly attributable to the quality of education that we are offering to our children.”

The relationship between school knowledge (curriculum) and the power structure due to continuous transformation and curriculum changes in South Africa place uncertainty around the reasons for curriculum change. Today, 20 years into democracy, young people's demands remain fundamental as there are still challenges and fragmentations in our education system. The maturity of any democratic society and the transformation of economic and social lived experience of a people depend on the access to good quality education (Ngubane 2014). The researchers allude to and agree with Apple (1979) in these questions: Whose knowledge, for whose benefit and at whose expense? The DBE might ask themselves these questions. It is also clear from the data that the new CAPS does not make enough provision for diversity in education or for learners with special education needs - areas where critical theory pleads for education to go beyond the mainstream approaches of inclusion to more critical innovative multiculturalists approaches. Participants found the level of prescription of CAPS was undermining their meeting the needs of the individual learners in their classes. Even if the DBE succeeds in overcoming the present huge challenge of successfully training all current teachers and providing textbooks on time, the idea of the DBE ever reaching the stage of quality education for all seems fanciful for many practical, societal and critical reasons.

\section{CONCLUSION}

The school is the embodiment of socialisation and therefore needs to be able to provide quality education. It is also highlighted by Vygotsky that social constructivism is basically a theory about how people create knowledge socially and that teaching forms an important part of creating knowledge. Linking with this theory, critical theory indicated the importance of the relationship between power and knowledge and that government should not misuse this power. On the topic of adapting to CAPS, some participants were of the opinion that they lacked the necessary knowledge and skills to meet all the existing challenges. It is thus important for governments to provide proper training for teachers to implement a new curriculum. Professional training of teachers needs to be ongoing, especially when a new curriculum must be implemented. This paper highlighted curriculum change and the premise that continuous professional development is necessary to empower teachers to implement a new curriculum. It also emphasised the importance of making interpretation and implementation guidelines available for the CAPS. The selection and development of the appropriate learning, teaching and support materials to enhance teaching and learning is deemed to be an important part of curriculum interpretation and implementation. It became clear in the course of the research that teachers needed to be better equipped for their role as educators. The DBE needs to take more seriously their calling to provide quality education for all.

\section{RECOMMENDATIONS}

The message for policy makers is that teachers need considerably more access to professional development, especially when a new curriculum is implemented, if they are to contribute to significant improvements in learner achievement. It is recommended that:

- in-service training for both teachers and school management teams must be made compulsory;

- schools should not only apply appropriate professional development policies but also ensure that they are implemented by means of efficient management and leadership;

- learning and teaching support material should be delivered on time;

- more research should be done by the DBE to develop a model for in-service training for teachers, and all stakeholders should be involved in the process.

- sufficient opportunities should be provided for support, interpretation, monitoring and assessment of any new curriculum by all stakeholders to contribute to the provision of quality education for all. 


\section{ACKNOWLEDGEMENTS}

The researchers want to thank the participants who took part in this research and $\mathrm{Mr}$ Nkeke Thosago (thosand@unisa.ac.za, 012337 6076) who edited this paper.

\section{REFERENCES}

Apple M 1979. Ideology and Curriculum. New York: Routledge.

Apple M 2001. Educating the 'Right' Way: Markets, Standards, God, and Inequality. New York: Routledge.

Apple M, Buras K (Eds.) 2006. The Subaltern Speak: Curriculum, Power, and Educational Struggles. New York: Routledge.

Biesta G 1998. Say you want a revolution ... suggestions for the impossible future of critical pedagogy. Educational Theory, 48(4): 499-510.

Buras K, Motter P 2006. Cosmopolitan multiculturalism. In: M Apple, K Buras (Eds.): The Subaltern Speak: Curriculum, Power, and Educational Struggles. New York: Routledge, pp. 5-11.

Cho S 2006. On language of possibility: Revisiting critical pedagogy. In: C Rossatto, R Allen, M Pruyn (Eds.): Reinventing Critical Pedagogy: Widening the Circle of Anti-oppression in Education. Lanham, MD: Rowman and Littlefield Publishers, pp. 24-25.

Coetzee A 2012. Presentation: NCS to CAPS by the Gauteng Department of Education. Paper presented in Seminar on NCS to CAPS. Kgorong Hall, UNISA, 31 May.

Darder A, Baltodano M, Torres R 2003. Critical pedagogy: An introduction. In: A Darder, M Baltodano, $\mathrm{R}$ Torres (Eds.): The Critical Pedagogy Reader. New York: Routledge Falmer, pp. 497-510.

Darder A, Baltodano M, Torres R 2004. After Race: Racism After Multiculturalism. New York: University Press.

Department of Basic Education 2010. Curriculum News: Improving the Quality of Learning and Teaching. Pretoria: Government Printer.

Department of Basic Education 2011a. Curriculum News: Improving the Quality of Learning and Teaching-Strengthening Curriculum Implementation from 2010 and Beyond. Pretoria: Government Printers.

Department of Basic Education 2011b. National Curriculum Statement Grades R-12, 11 September. From <http: //www.education.gov.za> (Retrieved on 4 June 2012).

Department of Education 2000. Norms and Standards for Educators. Government Gazette Volume 415 No. 20844. Pretoria: Government Printer.

Department of Education 2008. The Design of the Continuing Professional Teacher Development (CPTD) System. Pretoria: Government Printer.

De Vos AS, Strydom, H Fouché CB, Delport CSL 2011. Research at Grass Roots. $3^{\text {rd }}$ Edition. Van Schaik: Pretoria.

Du Plessis EC 2013. Do teachers receive proper inservice training to implement changing policies:
Perspective from the South-African case? Education in one world: Perspectives from, different nations. BCES Conference Books, 11: 53-58.

eNews 2012. 5000 Schools In Limpopo Province Don’t Have Textbooks. South African Television, 15 June, 2012.

Fourie H 2012. Books are Still Not Delivered at Schools in Polokwane. Beeld, October 3, P. 1.

Garai L, Kocski M 1995. Another Crisis in the Psychology: A Possible Motive for the Vygotsky-Boom. Journal of Russian and East-European Psychology 33(1): 82-94. From <http: //staff.u-szeged.hu/garai/ Vygotskyboom.htm> (Retrieved on 29 June 2012).

Gibson B, Gareth M 1979. Sociological Paradigms and Organizational Analysis: Elements of the Sociology of Corporate Life. Portsmouth, NH: Heinemann.

Giroux H 1992. Border Crossings: Cultural Workers and the Politics of Education. New York: Routledge.

Giroux H 1995. Insurgent multiculturalism and the promise of radical pedagogy. In: D Goldberg (Ed.): Multiculturalism: A Critical Reader. Oxford: Blackwell, pp. 325-343.

Giroux H 2004. The Terror of Neoliberalism: Authoritarianism and the Eclipse of Democracy. Boulder CO: Paradigm Publishers.

Giroux H, McLaren P 1994. Between Borders: Pedagogy and the Politics of Cultural Studies. Routledge: New York.

Government of South Africa 1996. No. 108 of 1996: Legislated: National Gazette No. 17678, 18 December. Pretoria: Government Printers.

Jansen J, Taylor N 2003. Educational change in South Africa 1994-2003: Case studies in large-scale education reform. Country Studies-Education Reform and Management Publication Series, II(1): 1-61.

Kalpana P 2014. A constructivist perspective on teaching and learning: A conceptual framework. International Research Journal of Social Sciences, 3(1): 27-29.

Klafki W 1983. Kategorial dannelse og kritisk konstruktiv pcedagogik (in German: Kategoriale Bildung). Copenhagen: Nyt Nordisk Forlag Arnold Busk.

Kramer D 1999. OBE Teaching Toolbox: OBE Strategies, Tools and Techniques for Implementing Curriculum 2005. Florida Hills: Vivilia Education.

Lekota M 2014. Quality of SA Education 'Mediocre'. News24. From <http: //www.news24.com/Sout-Africa/Politics?Quality-of-S A-education-mediocre2014-01-07> (Retrieved on 26 September 2014).

Lessing A, De Witt M 2007. The value of continuous professional development: Teachers' perceptions. South African Journal of Education 27(1): 53-67.

Lund T 2014. Poor Education 'Is Behind Joblessness'. Business Day, April 10, P. 1.

McLaren P, Farahmandpur R 2001. Class, cultism, and multiculturalism: A notebook on forging a revolutionary politics, Multicultural Education, 8(3): 511.

Ngubane M 2014. Education in South Africa 20 Years On: Quality and Safety in Schools Remain Priorities. From <http: //www.actionaid.org/south=africa/ 2014/06/education-south-africa-20-years-quality- 
and-safety-schools-remain-priorities $>$ (Retrieved on 28 September 2014).

Pinnock AJE 2011. A Practical Guide to Implementing CAPS: A Toolkit for Teachers, Schools Managers and Education Officials to Use to Assist in Managing the Implementation of a New Curriculum. Cape Town, South Africa: NAPTOSA.

Renato R 1993. Culture and Truth: The Remaking of Social Analysis. Boston: Beacon Press.

Smith C, Gillespie M 2007. Research of Professional Development and Teacher Change: Implications for Adult Basic Education. NCSALL Rep. No. 25. Boston: National Center for the Study of Adult Learning and Literacy.

Struwig FW, Stead GB 2013. Research: Planning, Designing and Reporting. $2^{\text {nd }}$ Edition. Cape Town, South Africa: Pearson.

Teacher Education 2010. Teacher Education in Wikipedia, the Free Encyclopaedia. From <http://en.
wikepedia.org/wiki/Teacher_education> (Retrieved on 23 August 2012)

Verheggen TH, Baerveldt C 1999. From shared representations to consensually coordinated actions, in theoretical issues in Psychology. In: JR Morss, N Stephenson, H Van Rappard (Eds.): International Society for Theoretical Psychology Conference. London: Sage.

Vygotsky LS 1962. Thought and Language. Cambridge, MA: M.I.T. Press.

Vygotsky L 1978. Mind in Society. London: Harvard University Press.

Wikipedia 2012. An Overview of Education. From <http://en/wikipedia.org/wiki/ Social_science> (Retrieved on 5 June 2013).

Wilkenson K 2014. Is SA Bottom of the Class in Maths and Science? WEF Ranking is Meaningless. Africa Check From <http: //africacheck.org/reports/is-sabottom-of-the-class-in-maths-and-science-whyranking-is-meaningless/\#comments $>$ (Retrieved on 3 September 2014). 